\title{
Chapter 7 \\ The Ecosystem Approach to Management in Baltic Sea Governance: Towards Increased Reflexivity?
}

\author{
Magnus Boström, Sam Grönholm, and Björn Hassler
}

\begin{abstract}
This chapter analyses the governance structures linked to the marine environment of the Baltic Sea. The purpose is to assess whether current developments of the governance structures have a potential to take into account requirements of an Ecosystem Approach to Management (EAM). We use the concept of reflexive governance to understand key components and weaknesses in contemporary governance modes, as well as to elaborate on possible pathways towards a governance mode more aligned with EAM. The reflexive governance framework highlights three elements: (1) acknowledgement of uncertainty and ambiguity; (2) a holistic approach in terms of scales, sectors and actors; and (3) acknowledgement of path dependency and incremental policy-making. Our analysis is based on a comparative case study approach, including analysis of the governance in five environmental risk areas: chemical pollution, overfishing, eutrophication, invasive alien species and pollution from shipping. The chapter highlights an existing governance mode that is ill-equipped to deal with the complexity of environmental problems in a holistic manner, with systematic attention to uncertainty, plurality of values, ambiguity and limited knowledge, while also pointing at important recent cognitive and institutional developments that can favour pathways towards reflexive governance and consequently EAM.
\end{abstract}

Keywords Baltic Sea $\bullet$ Ecosystem approach to management $\bullet$ Holistic approach • Marine governance $\bullet$ Reflexive governance

\footnotetext{
M. Boström ( $\square)$

School of Humanities, Education and Social Sciences, Örebro University,

SE-701 82 Örebro, Sweden

e-mail: magnus.bostrom@oru.se

S. Grönholm

Åbo Akademi University, Turku, Finland

e-mail: sgronhol@abo.fi

B. Hassler

School of Natural Sciences, Technology and Environmental Studies, Södertörn University,

14189 Huddinge, Sweden

e-mail: bjorn.hassler@sh.se 


\subsection{Introduction}

Our perceptions of what constitutes adequate marine environmental governance have undergone substantial changes during the last decades. From having been firmly based on biophysical problem framings, scientific risk assessments and endof-pipe solutions, integrated ecosystem approaches to management, stakeholder participation and adaptive governance are now what is on the table.

Marine environmental governance of the Baltic Sea has furthermore become more multifaceted than before, involving not only governments, international government organisations (IGOs) and other public bodies but increasingly also transnational networks of public authorities at substate levels, sector organisations, industry and non-governmental organisations (NGOs) (Hassler et al. 2011). The inclusion of non-public actors has to a considerable extent co-evolved with increased use of economic instruments such as differentiated levies, taxes and subsidies aimed at changing actors' behaviour through altered economic incentives (Hassler et al. 2011). Moreover, several scholars regard various forms of interaction between international conventions and EU directives as important parts of contemporary environmental governance (Oberthür and Gehring 2006; Stokke 2001; Young 2002).

Adding to the complexity of environmental governance, there is an increasing understanding among scholars that risk, uncertainty and ambiguity are key factors of the problems at hand (Gilek et al. 2011; Hassler et al. 2013; Lidskog et al. 2009; Renn 2008; Voss et al. 2006a; Walker and Shove 2007). Because of the systemic nature of marine ecosystems, a holistic approach needs to complement, and probably sometimes replace, the traditional emphasis on single species and tightly circumscribed risk assessments that exclude all except formal experts from assessment and management (Hassler et al. 2011, 2013). In many cases it is more reasonable to talk about uncertainty than risk (as conventionally understood within risk assessment), as limited knowledge in combination with stochastic processes makes estimation of probabilities for different outcomes difficult or not even possible (Hassler et al. 2011). Moreover, the notion of ambiguity implies that there is no obvious normative standpoint about preferable actions that comes from a particular risk assessment. Different stakeholders may have different interpretations of the perceived risks based on varied ethical, religious and political frames of reference. ${ }^{1}$

This chapter analyses the governance structures of the marine environment of the Baltic Sea. The primary goal is to assess whether current developments of the governance structures have a potential to take into account requirements implied by an ecosystem approach to management (EAM). When we talk about governance structures, we refer to the regulatory frameworks and institutions governing the marine environment of the Baltic Sea. The origin and evolution of large changes in governance structures is of particular interest. These changes are often initiated by

\footnotetext{
${ }^{1}$ Ambiguity or ambivalence refers to an object or event that simultaneously can belong to two contrasting categories (e.g. simultaneously loving and hating someone). A risk, such as driving fast or eating tasty but unhealthy food, often has both positive and negative denotations.
} 
governmental and other actors who have particular interests and capabilities with regard to specific environmental domains. Structural and discursive factors also shape conditions under which processes of change occur. We use the concept of reflexive governance as the main analytical vehicle to understand key components in contemporary governance modes, as well as to elaborate on possible pathways to make Baltic Sea environmental governance more sustainable.

This chapter is structured as follows: As EAM is increasingly seen as the manner in which governance should take place, we first provide a brief description of this management approach. We then give a brief description of the historical background to existing institutions and regulatory structures so as to understand contemporary Baltic Sea environmental governance structures and potential future pathways. Therefore, this chapter provides a section on key regional organisations, initiatives and regulations and highlights the increasing influence of the EU. This general background is then followed by an account of the concept of reflexive governance, which in turn forms the theoretical basis for the following extended analysis of contemporary governance structures with empirical examples from the areas of chemical pollution, overfishing, eutrophication, invasive alien species and pollution from shipping (see other chapters in the book). Finally, in Sect. 4, we discuss how the concept of reflexive governance can shed light on existing weaknesses of governance structures and how increased reflexivity could contribute to a more sustainable Baltic Sea.

In terms of method, our analysis is based on a comparative case study approach. The empirical data is drawn from five case studies conducted in the RISKGOV project. These case studies are documented in (Haathi et al. 2010; Hassler et al. 2010; Lemke et al. 2010; Sellke et al. 2010; Udovyk et al. 2010) and further analysed in Part I of this book (Hassler 2016; Karlsson and Gilek 2016; Karlsson et al. 2016; Sellke et al. 2016; Smolarz et al. 2016). The case studies were undertaken during 2009-2014 and were all based on secondary literature, analysis of key policy documents, semi-structured qualitative interviews with key actors in the respective risk areas (in total about 100) and participatory observations during conferences, workshops, consultations and round-table stakeholder conferences. A common analytical and methodological framework guided all five case studies which ensured comparability of the cases (see Gilek et al. 2016; Hassler et al. 2011 for further details).

\subsection{The Ecosystem Approach to Management (EAM)}

The Ecosystem Approach to Management (EAM), which endorses a multi-sector approach, has recently been embraced by key policy and regulatory actors. EAM underlies the Water Framework Directive (WFD), the Marine Strategy Framework Directive (MSFD), the EU Sixth Environmental Action Programme and even more so the EU's Baltic Sea Strategy and Maritime Policy.

EAM is a response to today's deepening biodiversity crises and promotes a broad holistic approach that goes beyond traditional management based on single species 
and single sectors (Curtin and Prellezo 2010; Grumbine 1994, 1997). EAM aims to provide a system of management that views the ecosystem as a whole, embracing ecological boundaries and integrity in such a way that all relevant ecosystem drivers and their impacts are considered in relation to their effects on ecosystem functioning and societal parameters. In broad terms EAM calls for adaptive, precautionary and knowledge-based measures across national and administrative borders to protect and restore key ecological functions of the environment (Backer et al. 2010). It is accordingly argued in EAM that management cannot be limited by administrative or political boundaries but needs to be delineated by appropriate biophysical boundaries. In this respect, institutional change and innovation is vital in dealing with and responding to institutional barriers (cf. Backer et al. 2010; Österblom et al. 2010). Emphasis is also given to interagency cooperation and promoting cooperation between various affiliated international, national and subnational management agencies. Furthermore, calls have been made for cross-sector integration, crosssector resource management and integration of information across disciplines and harmonising institutions (Barnes and McFadden 2007; Berghöfer et al. 2008; Murawski 2007). While acknowledging interaction between ecology and society, and the important role of stakeholder inclusion, the 'social dimension' (including environmental justice, quality of life, social cohesion, work etc.) of sustainable development has so far garnered less attention than the environmental dimension in EAM thinking (see Dreyer et al. 2011).

EAM acknowledges the complexity of ecosystems and the uncertainty related to management, realising that all factors affecting ecosystems are not well understood and may never be. In EAM, scientific knowledge is perceived to be provisional, because management is viewed as a learning process, incorporating the results of previous actions and allowing management to adapt to uncertainty. Learning about ecosystem processes and the interpretation and responses to ecosystem feedback at multiple scales requires different types of knowledge, not only scientific biological knowledge but also other types of knowledge gained from experience with concrete ecosystems (farming, fishing, recreation etc.) (Barnes and McFadden 2007; Galaz et al. 2008). Broadening of stakeholder engagement is a key component in EAM, not only to formalise existing knowledge but also to complement poor governance and data so as to find consensual solutions and legitimise the management process (Arkema et al. 2006; Curtin and Prellezo 2010; Murawski 2007; Tallis et al. 2010).

The concept of reflexive governance, which will be introduced later, shares several features of this perspective. Indeed, the very notion of reflexivity, which has to do with learning based on self-reference and self-critique, has affinities with the kind of adaptive management that EAM calls for. However, we are not just adding the theory of reflexive governance because it appears to fit well with EAM. Rather, to understand the conditions (barriers and opportunities) for a governance system to adopt features of EAM, we argue that it is important to learn from social scientific understanding of governance structures and processes. We also have to take into account a theory that helps us understand institutional change and inertia in a realistic way. We consider the theory on reflexive governance relevant and useful for that purpose (see also Hassler et al. 2013). 


\subsection{Evolving Environmental Governance}

Before the collapse of the Soviet Union, regional collaboration was more or less restricted to governmental discussions within the framework of the Helsinki Commission (HELCOM) and scientific collaboration at expert levels. The cold war placed strict limits on what was politically possible to achieve. According to some observers, HELCOM was primarily a means for the Soviet Union to find a relatively neutral ground for airing declarations mainly targeted at US audiences (Hjorth 1992). However, the early role of HELCOM as a first institutionalisation of regional collaboration for the protection of the Baltic Sea environment should not be underestimated (Hassler 2003b). During HELCOM's first two decades of existence, important scientific contacts were developed especially between researchers from Nordic countries and the Soviet Union. These Baltic Sea networks were important building blocks and resulted in several recommendations made by the still rudimentary, epistemic communities on concrete measure that could be taken with regard to ecological threats to the Baltic Sea environment.

Following the collapse of the Soviet Union, the declaration of independence of Baltic states and the democratisation of Poland in the early 1990s, four overarching changes affecting Baltic Sea environmental governance took place in the following two decades.

First, the liberation of the Baltic states and democratisation of Poland sparked off extensive bilateral support programmes from primarily Sweden, Finland and Denmark (Hassler 2003a). These programmes often involved governmental actors, such as municipalities and county boards, as well as non-governmental actors, for example, CECAMS (Centre for Environmental Science and Management) and Environmental Consultancy and Monitoring Centre, both from Latvia. ${ }^{2}$ In order to establish collaborative schemes, twinning agreements were made between donor and recipient countries (Hassler et al. 2011). In these agreements, a public authority or private company in the donor country collaborated with a counterpart in the recipient country in order to stimulate transfer of knowledge and know-how (Hassler et al. 2011). Financing was typically secured through government funds or international financial institutions such as NEFCO (Nordic Environment Finance Corporation), EBRD (the European Bank for Reconstruction and Development) and IBRD (the World Bank). In addition to these collaborative schemes, transnational initiatives were taken, such as collaboration among political parties, labour unions, NGOs and sector organisations. For example, political parties in Sweden and Finland collaborated with sister organisations in the Baltic states, and labour unions similarly had projects targeting areas such as gender equality and workplace democracy. Typically, these undertakings were partly financed by public sources (Hassler 2003a). Taken together, these new forms of interaction all contributed to

${ }^{2}$ CECAMS and the Environmental Consultancy and Monitoring Centre were both later on transformed into Latvian public agencies (Hassler 2003b). 
the strengthening of Baltic Sea governance and the possibility of deepened collaboration.

Second, the expansion of the EU, with Sweden and Finland becoming members in 1995 and the Baltic states and Poland in 2004, profoundly affected governance patterns as the Baltic Sea had now almost become a sea internal to the EU (Hassler et al. 2011). Only Russia among the Baltic Sea coastal states is not a member of the EU. National legislation had to be adapted to the common EU regulatory framework, and enforceable directives were added to the arsenal of steering mechanisms. Sizeable funds from EU's regional programmes were also a bonus. Apart from the direct effects the regulations and transposed directives have had on national legislation pertaining to marine environmental safety among the Baltic Sea EU member countries, new opportunities have evolved for strategically scaling up national and regional initiatives to the EU level in order to increase impact. Moreover, global conventions too have been scaled down, and provisions from these conventions added to the EU arsenal of enforceable law (Hassler et al. 2011). The vertical dynamics of Baltic Sea environmental governance has thus increased significantly over the last two decades.

EU programmes and EU-funded projects of various kinds moreover have exerted considerable and increasing influence on marine governance in the Baltic Sea region. The largest initiative so far has been the Baltic Sea Region 2007-2013 Programme comprising a total funding of 223 million euros plus national cofinancing. ${ }^{3}$ Apart from Baltic Sea EU member countries, Russia, Belarus and Norway are members of this Programme. Among its four priority areas, the third one is focused on the ecological integrity of the Baltic Sea in a wide sense (BSR programme 2012). The BSR programme is built on individual projects supported within the programme. Among the 80 projects funded, 20 are specifically targeting the Baltic Sea environment and concern areas such as maritime safety, climate change, eutrophication and aquaculture. ${ }^{4}$ It is clear that the substantial interactions among project members and associated partners - researchers, public authorities, companies, sector organisations, NGOs and other stakeholders - significantly affect contemporary Baltic Sea regional governance. Collaborations from this programme will continue with a new Interreg BSR Programme for 2014-2020.5

Taken together, the combined effects from EU regulation on the environmental status of the Baltic Sea, the increased dynamics in terms of interacting regulatory schemes at different levels, the growth of direct contacts between various stakeholders and EU authorities and the formulation of EU macro-regional programmes

\footnotetext{
${ }^{3}$ While a co-financing level of $25 \%$ is required for the more affluent Nordic countries and Germany, $15 \%$ is required from the Baltic states and Poland, whereas only $5 \%$ is the minimum in the case of Belarus (eu.baltic.net 2012).

${ }^{4} \mathrm{~A}$ project database comprising all BSR Programme projects is available at http://eu.baltic.net/ Project_Database.5308.html?

${ }^{5}$ For more info, see http://eu.baltic.net/Future_period_2014_2020.26029.html. Accessed 15 December 2014.
} 
have created a very different governance setup in the Baltic Sea region. The impact of this governance setup, however, has so far only been rudimentarily researched.

Third, the scope of what constitute environmental concerns has been broadened over the last few decades (Kern 2011). At first, they were narrowly perceived as management problems that in most cases could be dealt with by experts and through various technical solutions. Now what is asked for, not the least in several EU directives and policies, are multidimensional analyses, stakeholder involvement and system-wide management approaches. Stakeholder participation is typically emphasised not only as important in relation to public legitimacy from a normative standpoint but also as a means to bring in more knowledge to policy-making and make implementation more effective (Dreyer et al. 2011; Stirling 2009). Several EU directives have in this regard become increasingly important in the over-all governance of the Baltic Sea. A clear trend is that these directives are now more oriented towards holistic approaches to regulation and management. The Urban Wastewater Treatment Directive (91/271/EEC) and the Nitrates Directive (91/676/ EEC) were both decided upon before the EU was enlarged in 1995. This meant that neither Sweden and Finland nor the Baltic states and Poland shaped the directives but nonetheless had to more or less adapt them when becoming members. The Water Framework Directive (2000/60/EC) has had profound influence on, for instance, new forms of collaboration, since it calls for river basin management domestically and regionally and includes key stakeholders in decision-making processes. REACH, the EU regulation on chemicals (EC/1907/2006), does not directly target pollution of the seas and has many gaps (numerous chemicals are unregulated). It is, however, of significant importance in relation to the impact of various chemicals on marine ecological systems as it requires producers and users to improve registration, evaluation and information provision regarding substances and preparations of high concern. The Marine Strategy Framework Directive (2008/56/EC), finally, is the most recent directive on marine environments. Although it is yet too early to tell what impact it eventually will have, as with the other recent directives, its major ambition is to achieve Good Environmental Status by 2020 in all EU marine waters. Compared to earlier attempts to protect marine environments, the MSFD comprises a more holistic approach with an emphasis on adaptive management and participatory deliberation and centre-state biodiversity conservation (Dreyer et al. 2014). A similar trend towards holistic and inclusive approaches in general and the Ecosystem Approach to Management in particular is apparent for regional strategies and action plans. For example, in the 2007 HELCOM Baltic Sea Action Plan (BSAP), references to the ecosystem approach, integrated management and stakeholder participation are made as well to the need to better understand interactions between social and ecological systems. All member countries are required to submit national implementation plans for BSAP, covering all major areas related to marine governance of the Baltic Sea, including land-based pollution sources. However, to what extent BSAP will be able to profoundly influence management practice down to the local level and within implementing authorities is too early to tell. So far, implementation in Sweden has largely been traditional in the sense of not including elaborate strategies on how to improve 
stakeholder participation, deliberative processes and adaptive governance (Hassler et al. 2013).

The three above-mentioned trends all concern changes in government-centred structures, programmes and approaches, which in turn introduce new conditions for environmental governance structures and processes in the region. Fourth, an ongoing transnationalisation from below can be observed, which sets forth new conditions for both environmental governance of the Baltic Sea and reflexive governance. Various actors from different countries have developed forms and capacity for much tighter interaction and collaboration. Such interaction is facilitated by umbrella organisations for municipalities (e.g. Union of the Baltic Cities), or environmental NGOs (e.g. Coalition Clean Baltic), or by already transnational environmental NGOs such as WWF that connect different offices and establish new ones. ${ }^{6}$ By such increasing transnational collaboration and capacity building, business organisations, NGOs, municipalities and other non-state actors strengthen their abilities (viz. organisational, cognitive and other types) to participate effectively in environmental governance. In addition, they are able to increasingly by-pass national governments and approach EU authorities directly (sometimes through European-level umbrella organisations, such as the European Environmental Bureau), a policy track which they often find to be more efficient.

The four broad trends towards increased interaction among various stakeholders in the area of marine governance in the Baltic Sea region, the more institutionalised form and impact of EU governing and the evolving consensus on adopting systemic rather than particular approaches to environmental management add up to substantial changes in the preconditions for further marine governance improvements in line with EAM. In order to analyse these trends more thoroughly, we examine them from the perspective of reflexive governance.

\subsection{Reflexive Governance}

Reflexivity basically means self-reference. The concept of reflexive governance accordingly points to the need for strategic thinking on how to build institutions and governance modes that are, on the one hand, forward-looking and able to cope with uncertainties and other reasons for complex problems and, on the other hand, backward-looking and entailing self-critical scrutiny of the previous and current mode of governance (Voss et al. 2006a). Reflexivity entails reflecting upon the very governance process itself including its conditions: i.e. the extent to which existing boundaries, constitutions, discourses, policies, regulations, science-policy interactions and organisational arrangements produce and reproduce this generation of environmental problems. Reflexive governance thus includes a continuous selforiented examination of positive and negative outcomes (substantive dimensions;

\footnotetext{
${ }^{6}$ See Boström et al. (2015), Kern and Löffelsend (2004) and Van Deever (2011). See also Jönsson et al. (2016).
} 
sometimes understood as single-loop learning) as well as on how governance itself is related to these outcomes (structural/procedural dimension; sometimes understood as double-loop learning). ${ }^{7}$

We apply this theoretical framework to shed light on our five focused cases of marine environmental governance. We ask if relevant arrangements and discourses have been developed that enable such reflexivity. A number of factors may hinder or facilitate such reflexivity but we do not attempt an exhaustive analysis. Based on the existing work on reflexive governance, we develop an ideal type that consists of three elements that appear essential for reflexive governance and which guide our analysis of the Baltic Sea marine environmental governance arrangements. These elements are:

1. Acknowledgement of uncertainty and ambiguity

2. Holistic approach in terms of scales, sectors and actors

3. Path dependency and incremental policy-making

The first element is acknowledgement of uncertainty and ambiguity. Reflexive governance involves recognition that global and local sustainability problems are extremely complex, uncertain and ambiguous and need to be handled as such. Problem handling requires transgressing existing cognitive and institutional boundaries (Voss and Kemp 2006). Reflexive governance thus stresses that problems often cannot be 'solved', in the strict sense of the word, only handled. New problems or trade-offs tend to appear after decisions are made. Decisions tend to involve compromises. Surprises appear over and over again. The crucial question is if governance has any potential to continuously respond to such surprises.

The concept reflexive governance relates to Ulrich Beck's theory of the world risk society and reflexive modernisation $(1992,1994)$. Beck connects late modern risks to how societal spheres and institutions (technology, science, politics, the state, the economy) in the 'simple' or 'first' modernity operated according to the Enlightenment Project. Instrumental, rational problem-solving during 'simple' modernity relied on a cognitive and institutional approach in which uncertainty, complexity and ambiguity were disregarded. Problem-solving was specific and straightforward - based only on single-loop learning - and the goal was maximising the control of social and economic development. However, this approach inevitably leads to many unintended, negative consequences, at first called 'side effects'. As these are multiplied and increasingly seen as unresolved within traditional instrumental approaches, a reflexive turn emerges or in Beck's words reflexive modernisation (or 'world risk society').

The second element is a holistic approach in terms of scales, sectors and actors. As problem handling requires the possibility to transgress existing discursive and

\footnotetext{
${ }^{7}$ Metaphorically, single-loop learning is sometimes compared with a thermostat, which continuously makes adjustments based on incoming information (it is too hot), whereas double-loop learning is involved in searching for why a problem appears in the first place (why is it too hot). The second type of learning involves asking questions about the less apparent assumptions, values or governing factors underlying the system.
} 
institutional boundaries (as emphasised in the first element above), it is essential that a variety of actors take part in the debate and search for solutions. The theory on reflexive governance, like EAM, acknowledges interdependencies across scales, sectors and arenas of governance, which in turn necessitates cooperation and dialogue among a variety of actors. The key question to address is whether there are arenas, forums and networks that allow for multi-actor, multi-scale as well as intersectoral collaboration and reflexivity. On a transnational regional level (e.g. the Baltic Sea region), this question and challenge is accentuated even more because institutional structures are traditionally developed within the system of sovereign nation states.

The theory of reflexive governance moreover has clear similarities with EAM and with scholarly writing about adaptive (co-)management in terms of the endorsement of a learning and dynamic view on governance (e.g. Hahn et al. 2006; Olsson et al. 2004), as well as regarding the important role of multiple actors in goal formulation, knowledge production and decision-making. While adaptive co-management primarily focuses on ecosystems, particularly at the local level, reflexive governance highlights the role played by social critiques at various levels. Social critique (or social reflexivity; cf. Beck 1992, 2006) plays a potentially constructive role for social and institutional learning. For individuals, organisations and institutions to be able to scrutinise themselves, they need to be open to the public confronting them about how their practices contribute to the production and reproduction of problematic circumstances. The reflexive governance perspective accordingly pays key attention to the importance of public debate and the monitoring role of civil society organisations and other actors.

The third element is recognition of path dependency and incremental policymaking. Acknowledgement of path dependency warrants, in turn, a consideration of incremental policy-making and step-by-step transformation. Radical and immediate shifts towards EAM in the complete sense are infeasible. In any governance arrangement, there are a number of exogenous and endogenous factors that serve to reproduce existing institutional structures (e.g. economic incentives, existing institutional boundaries, discourses, vested interests, habits, cognitive limitations and bounded rationality): "the existing structure fight back" (Grin 2006: 74). Thus, socialecological transformation is typically path dependent, and existing physical and institutional structures significantly shape ambitions to work towards sustainable development. However, forward-looking and careful efforts to avoid and escape lock-in effects are possible even in an incremental approach to policy reform, Kemp and Loorbach (2006) argue. Moreover, path dependency also means that continuing along existing paths sometimes is preferable to keeping too many doors open as prior investments, learning and experiences then can be made use of, making capacity growth cumulative. 


\subsection{Analysis of Reflexivity in Baltic Sea Environmental Governance}

\subsubsection{Acknowledgement of Uncertainty and Ambivalence}

Acknowledgement of uncertainty and ambiguity includes a willingness to actively explore uncertainty and ambiguity and develop preparedness for unintended consequences. Unintended consequences are impossible to eliminate completely and therefore have to be prepared for. This preparedness has to be both discursive and institutional. EAM and reflexive governance acknowledge an open-ended, experimental and learning-oriented approach, 'in the course of modulating ongoing developments, rather than towards complete knowledge and maximisation of control' (Voss and Kemp 2006: 7). Acknowledging uncertainty is thus something more than just a matter of trying to close information or knowledge gaps (Lidskog et al. 2009: 131-2). Reflexive governance entails an awareness that current modes of risk governance potentially could produce new side effects, new risks. Institutional and technological structures need to be forward-looking and adaptive, allow for trialand-error learning and experiment with new innovations (Grin 2006; Kemp and Loorbach 2006).

While interviewees in the five case studies in general acknowledged the complexities and uncertainties surrounding environmental risks (regarding causes and effects), they seldom used tools to systematically take into account uncertainties and ambiguity; particularly those that stem from combined risks (e.g. cocktail effects regarding chemical risks). Our analysis showed that environmental risk governance of the Baltic Sea, in general, does not yet acknowledge these combined risks adequately. Risk assessment tends to go on as usual in the various sectors (Hassler et al. 2011, 2013). In none of the cases did we find any specific mechanisms, strategies or guidelines for systematically dealing with uncertainty and ambivalence. While the precautionary principle is increasingly invoked as a means to cope with uncertainty, actors rarely reflect upon how this principle should be implemented in practice. Having said that, what the case studies also show is that there is at least a growing recognition among scientists and other stakeholders that science alone cannot provide answers to all questions (see also Linke et al. 2016).

\subsubsection{Holistic Approach in Terms of Scales, Sectors and Actors}

A holistic approach entails preparedness for (1) multi-scale, (2) multi-sector and (3) multi-actor approaches to problem handling. 


\subsubsection{Multi-scale}

First, multi-scale aspects include the possible need to shift scales - rescale - and deal with problems that go beyond existing geographical boundaries. There is no universal model here. Functional spaces may differ between risk areas, which can lead to considerable problems for the governance system. 'In short, the interaction space needs to be congruent with the problem space' (Voss et al. 2006a: 427). It is more the rule than the exception that environmental risks are transnational in character, implying that the robust handling of such risks necessitates the parallel development of new kinds of political and regulatory arenas, frameworks, actors and interactions that better correspond with the problem structures (cf. Lidskog et al. 2009). The cases of overfishing and eutrophication are most clearly regional problems and collective bads, which require regional collaboration. Yet, existing regulatory failures in these areas (see relevant chapters in the book) are not only due to the fact that the Baltic Sea countries are different. They are also due to the fact that these countries are affected differently, which poses more challenges to joint collaboration at the regional level. Depending on the size of costs and benefits (increased/improved ecosystem services), governments tend to adopt somewhat different strategies and have different ambitions when it comes to implementation, monitoring and enforcement.

Key EU directives and strategies may help to establish a regional approach to problem handling. We see in the cases of agriculture (Karlsson et al. 2016) and fishing (Sellke et al. 2016) a comparatively integrated approach at the European level to problem handling. A platform exists for the search for improved environmental risk governance. The EU can thus potentially help to move beyond a merely national view on what are regional problems. The fact that Baltic Sea countries have joined the EU in different enlargement phases and thus have had unequal amounts of time to adapt to EU regulations and practices, and also have very different political and economic backgrounds, makes it complicated to assess the full impact of the EU. One stated problem is that the relatively centralised EU regulatory framework has prevented sustainable regional solutions in these two sectors, although there are signs of regionalisation in the case of overfishing.

The cases of invasive alien species, oil spills and chemical pollution (see relevant Smolarz et al. 2016; Karlsson et al. 2016; Hassler 2016) exemplify regional risks relating to global flows of raw material, products and people. The management of these risks is more than in the other cases dependent on linking regional governance to global frameworks. For example, there are some elements in the European chemical regulation that serve to combine regional governance with a global kind of horizontal governance (along global product chains). Importers (public and private) need to be better aware of the chemical contents in products, which in turn means that they have to facilitate steering mechanisms, dialogue and information sharing with suppliers in other parts of the world (Boström et al. 2012; Boström and Karlsson 2013). However, this kind of combination of regional/global as well as vertical/horizontal aspects of governance is only in an embryonic stage. There is still a strong unmet demand for institutional/international cooperation. 
The International Maritime Organization (IMO) plays a crucial role in the case of oil spills and appears to be a regulatory body that can relatively well foster and institutionalise such collaboration (Knudsen and Hassler 2011; see also Hassler 2016). The case study on IAS, in contrast, illustrated the existence of an embryonic global regulatory framework, the International Convention for the Control and Management of Ships' Ballast Water and Sediments (BWMC). This convention, however, has not yet (August 2015) entered into force. ${ }^{8}$

HELCOM has played an important role with regard to all these issues by establishing a political and regulatory space at the regional level and more recently through harmonising its regulations with EU regulations (Kern and Löffelsend 2004: 124). Although HELCOM lacks strong enforcement mechanisms, several interviewees we spoke to emphasised the many important roles that HELCOM plays. They said that HELCOM embodies an important part of the governance structure, as it is the only regional forum for negotiations where the entire BSR (Baltic Sea region) is represented, including Russia. It also plays an important role in linking Russia with the EU in debates and policy-making. HELCOM furthermore increasingly serves as an important arena for information sharing, negotiations and policy-making (e.g. Boström et al. 2015; VanDeever 2011), despite the parallel strengthening of EU competence in the Baltic Sea region.

HELCOM helps to coordinate countries in areas where there are many, partly overlapping and conflicting regulations (eutrophication, chemical case). It provides data and action plans (BSAP) and identifies hotspots. Based on such information, national NGOs as well as public authorities can then promote the implementation of programmes, projects and decisions made by HELCOM. HELCOM can thus function as an important reference point - a cognitive authority rather than rule-setting authority - for nationally based campaign organisations. HELCOM can also take a proactive approach in issue areas that are poorly developed.

\subsubsection{Multi-sector}

Second, the multi-sector notion acknowledges interdependencies across various sectors and arenas of governance, a key concern according to the EAM perspective. While we see clear paths towards institutionalisation of regional organisations and collaboration within sectors, there is less evidence of institutionalised collaboration across sectors. Governance so far has coped with this complexity primarily on the discursive level, i.e. by many authorities endorsing EAM, but not translating it into reformed practices. All case studies reveal substantial difficulties to translate this principle into practice. Each issue area has been traditionally handled separately by regulations and institutions, both nationally and within the EU. Governance relies on various assessment and management techniques (such as the total allowable catch system in the overfishing case) that are difficult to reconcile with EAM.

\footnotetext{
${ }^{8}$ The status of IMO Conventions can be checked at http://www.imo.org/en/About/Conventions/ StatusOfConventions/Pages/Default.aspx
} 
However, the potential role of HELCOM could be highlighted. It is not only a body that contributes to the carving out of a regional regulatory and political space. It is also a multi-issue organisation. According to our informants in HELCOM, different sections and working groups usually work separately. Yet, it is not hard to imagine that the increasing focus on EAM could pave the way for more systematic cross-sector collaboration (e.g. committees, working groups) within the organisation. A limit, on the other hand, is that while HELCOM may be able to achieve integration among environmental issues, it may face difficulties to reach out to other sectoral interests (agriculture, fishery).

It is likely that day-to-day concrete management of environmental risks in the Baltic Sea, as in other regions, will continue to be undertaken within sectoral administrations. The need for expertise, experience, hardware and specialised institutional structures makes this almost unavoidable. However, the initiatives with HELCOM forums - HELCOM AGRI/ENV Forum and FISH/ENV Forum - where public administration representatives of environmental and natural resource use sectors regularly meet to discuss the implementation of BSAP are interesting possibilities and could prove to be valuable in bridging sectors.

\subsubsection{Multi-actor}

Third, the multi-actor notion stresses the need to integrate the plurality of values and interests by using democratic procedures. Moreover, the need for transdisciplinary knowledge production, as well as co-production of knowledge among various types of knowledge holders needs to be acknowledged (Kemp and Loorbach 2006). Stakeholder inclusion is generally seen as a necessary element in reflexive governance (see also Jönsson et al. 2016). Different actors can shed additional light on common problems. Various sector organisations, NGOs and citizens can engage in social critique and environmental monitoring (Mol 2008), which potentially provide essential input to reflexive governance. These actors make observations, undertake collections and compile and interpret data - in parallel to governmental bodies and scientists doing the same - and then engage in framing and politicising of issues. It is important that monitoring is diffused among a plurality of actors, since this widens the way environmental risks are perceived, measured or estimated, which in turn can increase likelihoods that less appropriate methods and practices are weeded out. The simple fact that similar risks are approached from somewhat different angles can stimulate discussions on methods and methodology and contribute to refinement of environmental risk monitoring.

The case studies definitely show there are lots of stakeholders involved in governance and environmental monitoring. The Baltic Sea region scores relatively well as a marine region in terms of development of transnational networks (Joas et al. 2008; Kern and Löffelsend 2004). The interplay between HELCOM and non-state actors has been expanded (Van Deever 2011). HELCOM has undergone an attitude change and nowadays allow for non-state actors to take part as observers and even organises stakeholder conferences (Dreyer et al. 2011; Linke et al. 2016). Recent innovative 
forums include the Regional Advisory Councils in the fishing sector (see also Dreyer et al. 2014).

Nonetheless, there is a striking lack of institutionalised structures for stakeholder participation and communication, particularly at the regional level. And in general, there is a fairly big gap between ideal scenarios and practice when it comes to broad stakeholder participation and communication of environmental risk governance of the Baltic Sea (including the EU level) (Dreyer et al. 2011, 2014; Jönsson et al. 2016; Linke et al. 2016). From the case studies, we found scant evidence of real reflection on and practice of participatory and communication activities. Forms for horizontal interaction among groups are generally lacking (exceptions are umbrella NGOs such as Coalition Clean Baltic). HELCOM and other governance arrangements are only beginning to foster such horizontal interaction. Available forms of stakeholder interaction are fragmented and only allow for some restricted inclusion of various stakeholders, as within the EU WFD. The institutional design of the RACs presents one of the most innovative and interesting models. Yet, the RACs only apply to the risk management phase, not earlier phases during, for example, risk assessment and risk appraisal when the problem framing mainly occurs (see Dreyer et al. 2014; Sellke et al. 2010). Furthermore, there is a dominant functionalist view of participation in which stakeholders are at the service of policy. By interpreting the data from the cases studies, it is clear that stakeholders are supposed to improve implementation and provide useful knowledge to policy, but not expected to express their values or provide criticism based on reflexive thinking (social reflexivity in Beck's understanding). If the risk assessment arrangement relies on a narrow scientific-technical framing, which was particularly apparent in the eutrophication case, the governance framework in effect largely excludes stakeholders' knowledge and experiences and undervalues their potential input.

However, the critical issue is not merely that of increasing inclusion. While addressing tensions between inclusion of stakeholders and decision efficiency, Voss et al. (2006b) make an important observation by referring to an 'efficacy paradox', between 'opening up' for the inclusion of more actors and 'closing down' for decision-making. The more actors that become involved, the trickier the decisionmaking process is likely to be. This paradox, or tension, cannot be eliminated but needs to be recognised and somehow organisationally balanced. Although vast networks of international substate, city networks or lobby organisations exist within the BSR (see Fig. 3.1. in Haahti et al. 2010: 23), their participation is to a large extent predetermined by the character of the regulatory framework, making their role more indirect, i.e. attending meetings and participating within, for example, HELCOM according to their 'observer' status. But, due to the vastness of the NGO networks, competition among networks, for example, for funding and hence domination, this has in some cases resulted in overlapping and conflicting agendas. A perception that there are too many actors engaged is likely to emerge if there are a lack of clear forms and structures for stakeholder input as well as a lack of rules and guidelines that define the roles and relationships among stakeholders. Absence of structures for stakeholder participation and communication corresponds with a lack of coordination among actors. Furthermore, it should be carefully noted that 
reflexivity within the stakeholder participation process will suffer if the dominant participants guard too close their specific interests. For example, it was illustrated in the case studies on eutrophication and overfishing that sector interests (agriculture and fisheries, respectively) made reflexivity, open-ended discussions and long-term strategic thinking problematic. In other areas, where stakeholders do not have such strong sectoral interests to defend, progress is more likely.

Finally, it is important to acknowledge that a plurality of actors each can take their own initiatives and a central place in the development of rules, policies and guidelines. Examples of such initiatives include voluntary agreements between public and private actors, codes of conduct that companies use in interaction with suppliers, eco-certification and labelling and guidelines for sustainable procurement and other practices. The perspective of reflexive governance stresses that this role is not limited to governmental actors (on either the national or international level). Often there is a need for voluntary approaches initiated by non-governmental actors (either for profit or not for profit) when the regulatory space is diffuse and relatively unregulated. Some actors take initiatives and suggest templates (which the intergovernmental actor HELCOM also does). It is interesting to note that businesses take their own initiatives and engage in risk assessments and research in order to develop technical solutions. This cannot just be dismissed as greenwashing but could indicate also instances of reflexivity, as it occurs as a response to the slow implementation of existing regulations. In the case study of IAS, business actors took own rule-making initiatives, and it was reported that companies encouraged states to ratify the convention. As long as shipping companies can continue their business in a technically and economically feasible way, there is no self-evident reason for them to counteract environmentally sound regulation. As Young observes (2009: 25), 'corporate actors are frequently more concerned with the development of stable rules and a uniform and predictable regulatory environment than with the exact content of the resultant governance systems'. Voluntary rule-making can sometimes, in effect, appear as strict and compelling as mandatory regulation (or even more strict, because there can be considerable interpretative flexibility and room for manoeuvre within measures that are defined as mandatory). Delmas (2009) explains this observation by referring to March and Olsen's well-known distinction between 'the logic of consequences' and 'the logic of appropriateness'. The first one relates to calculation of positive economic or noneconomic benefits for individual and collective actors, whereas the latter refers to when actors respond to cognitive or normative pressures in order to establish legitimacy or avoid their reputations from being damaged. Soft approaches can very well relate to both these types of logics. A combination of voluntary rule-making and mandatory regulation is also necessary in the cases when global flows of raw material and products relate to the regional risks and where effective global conventions are absent (Boström and Karlsson 2013). The mix of hard and soft approaches should accordingly be seen as context dependent and could thus be adjusted depending on the scale and scope of the problem structure. 


\subsubsection{Path Dependency and Incremental Policy-Making}

The reflexive governance perspective underscores the importance of taking path dependency seriously. Arguably, considerable reflection is required to determine when incremental, step-by-step transformation is appropriate rather than searching for utopian policies, or policies that might seem optimal but unfeasible for various reasons (Grin 2006; Kemp and Loorbach 2006), and when it is wiser to continue with prior investments and already selected paths. While path dependency metaphorically denotes a barrier to change, one could also see it in more positive light, namely, as 'pathways'. Are there any windows of opportunity to overcome lock-in effects and induce new pathways, which on the one hand will create a level of path dependency in the future, but on the other could be seen as a more favourable path? The search for such pathways requires reflexivity.

Some of the dominant intergovernmental organisations in relation to environmental risks in the Baltic Sea have comparably long histories. HELCOM is experiencing its 40-year anniversary, IMO has already turned 60, and the International Council for the Exploration of the Sea (ICES) has a history that goes back all the way to 1902. Although they all have evolved over time and affected by external and internal change pressures, large organisations tend to change only slowly. This is natural as procedures, practices and expectations become increasingly established and part of the organisation's identity. Moreover, as long as most of the staff remains part of the organisation for a long time, change is often circumscribed because of existing expertise and the perspectives adopted by leading experts and administrators within the organisation. This may sometimes create organisational inertia and a limited ability to adapt to changing societal expectations (Ahrne and Papakostas 2002). However, the experiences, know-how and expertise that have been built up in the organisations over time can also be important assets. The authority and influence exerted by these organisations are often the result of well-established expertise (Barnett and Finnemore 2004).

It is important to note that both aspects - potential organisational inertia and established expertise - contribute to path dependency, namely, difficulties in changing perspectives such as moving from a traditional reductionist and sector scientific perspective to the ecosystem approach to management. From a policy perspective, this needs to be carefully assessed in relation to the creation of space for reflexivity. Looking, for example, at the emerging attention being given to fishery and eutrophication issues by HELCOM, it is possible that a strengthened role for HELCOM in these areas will increase the weight given to traditional scientific practices (singleloop learning), as it is with these practices that the organisation has its strongest merits. On the other hand, it is also possible that HELCOM entering into less chartered areas, creating new committees and working groups end engaging new types of experts will create opportunities for the adoption of new perspectives, perspectives based on contemporary thinking on sustainability and holistic ecosystem approaches (double-loop learning). Compare this with the contemporary trend towards EU regionalisation in fisheries where new bodies (RACs) have been set up 
according to the perceived importance of stakeholder participation, utilisation of different forms of knowledge and decentralisation. Here, the creation of new organisational bodies creates space for new thinking and breaking up of organisational inertia, while at the same time previously built up experience and knowledge to some extent may be lost (see also Hassler et al. 2013 about recent and current developments in ICES, in which organisational change opened up possibilities for increasing reflexivity).

It should be noted that not only organisations can be trapped in various forms of path dependency, but individual sectors as well, not least so in ways of thinking and perspectives adopted. It is possible that the fishery sector in the EU to a considerable extent suffers from what may be called TAC path dependency (Hassler et al. 2013; Sellke et al. 2010, 2016). Reflection on how to better manage Baltic Sea fish stocks is still hampered by traditional thinking on maximum sustainable yield (MSY) and TACs that makes elaboration of concrete management plans based on EAM slow to emerge. Somewhat similarly, eutrophication caused by agriculture seems to be trapped in a reductionist thinking regarding natural resource management, where the EU/CAP system often sets the agenda for discussions and circumscribes what is brought to the table (Karlsson et al. 2016; Haahti et al. 2010).

The breaking loose from negative aspects of path dependency is difficult. Established organisations are often inert and slow to change, historic investments create vested interests, and expert and public deliberation is often dominated by prior discourses. However, one way to move forward can be to establish new institutions for discussion and reflection and stimulate new projects or programmes in established organisations by providing ear-marked funding and support to organisations entering new areas. One example are HELCOM's forums for cross-sector discussions between on the one hand the agriculture and environment sectors and on the other the fisheries and environment sectors. An argument could be made that this 'institutional redundancy' where several organisations deal with the same risk sector - but based on different perspectives and approaches - could, in fact, in the long run be better than too much streamlining and specialisation. Considering the tremendous difficulties in reforming CAP and CFP to fall more in line with sustainability ambitions, different ways to find new perspectives and approaches are without question badly needed.

\subsection{Towards EAM and Reflexive Governance?}

The contemporary system of environmental governance in the Baltic Sea predominately emphasises single species and tightly circumscribed risk assessment procedures that tend to exclude all other expertise and even formal experts from decision-making and management. The rationale for new forms of governance is that the traditional governance mode is ill-equipped to deal with the complexity of environmental governance in a holistic manner, namely, giving systematic attention to uncertainty, plurality of values, ambiguity and limited knowledge. 
Substantial amounts of uncertainty necessitate risk assessments drastically different than those done in the traditional way. Governance modes need to be developed that focus more on how to handle uncertainties and induce reflexivity on existing paths and possible futures, rather than on finding exact predictions on hazardous effects and outcomes. Moreover, all five risk areas are characterised by significant amounts of ecological and social complexity. These complexities make governance challenging. Issues such as regulatory overlap and overload, antagonistic institutional interactions, lagging enforceability, unbalanced inclusion of stakeholders, slow regionalisation, poor risk communication and several others are urgently needed to be addressed in all five areas addressed in this book. A particularly crucial issue discussed in this chapter is the, oftentimes cemented, sectorisation that prevents interaction and learning across sectors. Despite the variation in solutions that most likely is needed, learning across risk areas can potentially improve over-all environmental safety levels and benefit long-term sustainability. While we found very little of such cross-sector interaction, early attempts in organisations such as HELCOM and ICES do indicate fruitful pathways and signs of emerging reflexivity (Hassler et al. 2013).

Although comprehensive regulatory frameworks for managing the Baltic Sea are mostly in place, existing institutional structures accordingly lack a holistic approach to management, as the structures are often sector driven and based on sectoral governance that often excludes cross-sector cooperation and reflection. In addition, different regulatory frameworks contradict each other and constitute a confusing totality. The results from the case studies show that the traditional emphasis on single species and tightly circumscribed risk assessments that rely on narrow scientific-technical framings still dominate, despite a broader and increasing recognition of the problems with these narrow views. There are many stakeholders around demanding attention. However, the structures that would facilitate fruitful coordination and deliberations among them are few, limiting and vague (see also Jönsson et al. 2016). Existing institutions are thus inclined to exclude co-management while mechanisms of path dependency are likely to force actors to stick with 'business as usual'. Managing the Baltic Sea entails substantial amounts of uncertainty due to ecological and social complexity, but there is an apparent lack of scientific interdisciplinary integration, linking natural and socio-economic science in assessing the complexity of risk sources, as existing assessment is primarily based on natural science. The institutional structures also tend to overlook how to deal with scientific uncertainty, although there appears to be growing awareness among scientists and other stakeholders that science alone cannot provide all the answers.

The ability to address EAM is a matter of dealing with inert organisations, path dependency and decision-making systems based on a short-term focus. As we have stressed, the concept of reflexive governance points to the need for strategic thinking on how to build institutions and governance modes that are both forward- and backward-looking, which entails reflection - double-loop learning - on the very governance process itself including its conditions. Such reflexivity cannot be done and induced from one vantage point, but rather from a plurality of them. Problem handling requires the possibility to transgress existing discursive and institutional 
boundaries. A precondition for such transgression is that a variety of actors can take part in the debate and search for solutions.

The EAM concept has potential to facilitate such type of reflection, but only if social sustainability issues such as participation, justice, quality of life and social coherence are more pronounced (see Boström 2012 for a discussion regarding social sustainability). Innovative concepts such as EAM may not induce quick changes but could still have an important role to play in the long run. New concepts bring new ways to frame problems and solutions and can open up new spaces for interaction and dialogue among actors and consequently for mutual learning among them. Thus, we should not be too hasty in assessing or neglecting the potential of EAM to bring about change. EAM does, indeed, bring reflexive potential to criticise traditional risk assessment and management (such as the TAC machine) and can open up doors at the cognitive level. EAM helps actors to look for new 'pathways'.

However, concepts such as EAM are not sufficient to accomplish such tasks on their own. Institutional and organisational structures that provide interactive space and remove obstacles for such reflexivity also need to be in place. This is only beginning to happen in regional governance of the Baltic Sea. Institutional structures appear even more inert than cognitive structures. While many interviewees used the rhetoric of sustainability, ecosystems, uncertainty, precaution, holism, cocktail effects and so on, they were unable to translate new ideas into feasible operations. On the institutional level, a welcome development is, however, the increasing cross-border interaction and capacity building that have emerged from both above and below. Tighter interaction and capacity building among non-state actors, for instance, provide better conditions for constructive input to policy at this cross-border regional level. It should be remembered that input from non-state actors is crucial not only in the more instrumentalist/functionalist way (for the service of current governance) but also in the more reflexive/critical way (social reflexivity). The latter is so because the incessant push for change is arguably needed to prevent the current governance system from relapsing into business as usual while only rhetorically committing to EAM.

Acknowledgements This chapter draws on results from the research programme 'Environmental Risk Governance of the Baltic Sea' (2009-2015; Michael Gilek, programme coordinator) and involved research teams from Södertörn University in Sweden, Åbo Akademi University in Finland, Dialogik/Stuttgart University in Germany and Gdansk University in Poland. The funding came from the Foundation for Baltic and East European Studies and the European Community's Seventh Framework Programme (2007-2013) under grant agreement no. 217246 made with the joint Baltic Sea research and development programme BONUS, as well as from the German Federal Ministry of Education and Research (BMBF), the Swedish Environmental Protection Agency, the Swedish Research Council FORMAS, the Polish Ministry of Science and Higher Education and the Academy of Finland. We wish to express our warmest thanks to these institutions for enabling us to conduct this research, to all participants in the research programme that directly or indirectly provided useful input, to all informants who shared their experiences and to the two reviewers for their constructive comments on an earlier version of the chapter. 
Open Access This chapter is distributed under the terms of the Creative Commons AttributionNoncommercial 2.5 License (http://creativecommons.org/licenses/by-nc/2.5/) which permits any noncommercial use, distribution, and reproduction in any medium, provided the original author(s) and source are credited.

The images or other third party material in this chapter are included in the work's Creative Commons license, unless indicated otherwise in the credit line; if such material is not included in the work's Creative Commons license and the respective action is not permitted by statutory regulation, users will need to obtain permission from the license holder to duplicate, adapt or reproduce the material.

\section{References}

Ahrne G, Papakostas A (2002) Organisationer, samhälle och globalisering: tröghetens mekanismer och förnyelsens förutsättningar (in Swedish). Studentlitteratur AB, Lund

Arkema KK, Abramson SC, Dewsbury BM (2006) Marine ecosystem-based management: from characterization to implementation. Front Ecol Environ 4(10):525-532

Backer H, Leppänen JM, Brusendorff AC, Forsius K, Stankiewicz M, Mehtonen J, Pyhälä M, Laamanen M, Paulomäki H, Vlasov N, Haaranen T (2010) HELCOM Baltic Sea Action Plan a regional programme of measures for the marine environment based on the ecosystem approach. Mar Pollut Bull 60:642-649

EU Balticnet (2012) Fact sheet, May 2012

Barnes C, McFadden KW (2007) Marine ecosystem approaches to management: challenges and lessons in the United States. Mar Policy 32:387-392

Barnett M, Finnemore MA (2004) Rules for the world. International organisations in global politics. Cornell University Press, London

Beck U (1992) Risk society. Towards a new modernity. Sage Publication, London

Beck U (1994) The reinvention of politics. Towards a theory of reflexive modernization. In: Beck U, Giddens A, Lash S (eds) Reflexive modernization. Politics, tradition and aesthetics in the modern social order. Polity Press, Cambridge

Beck U (2006) Reflexive governance: politics in the global risk society. In: Voss JP, Bauknecht D, Kemp R (eds) Reflexive governance for sustainable development. Edward Elgar, Cheltenham, pp 31-56

Berghöfer A, Wittmer H, Rauschmayer F (2008) Stakeholder participation in ecosystem-based approaches to fisheries management: a synthesis from European research projects. Mar Policy 32:243-253

Boström M (2012) A missing pillar? Challenges in theorizing and practicing social sustainability. Sustain: Sci Pract Policy 8(1):3-14

Boström M, Karlsson M (2013) Responsible procurement, complex product chains and the integration of vertical and horizontal governance. Environ Policy Gov 23(6):381-394

Boström M, Börjeson N, Gilek M, Jönsson AM, Karlsson M (2012) Responsible procurement and complex product chains: the case of chemical risks in textiles. J Environ Plan Man 55(1):95-111

Boström M, Rabe L, Rodela R (2015) Environmental non-governmental organizations and transnational collaboration in two macro-regional contexts: the Baltic Sea and Adriatic-Ionian Sea regions. Environ Polit 24(5):762-787.

BSR programme (2012) Executive summary. Available from: http://eu.baltic.net. Accessed 23 May 2012

Curtin R, Prellezo R (2010) Understanding marine ecosystem based management: a literature review. Mar Policy 34:821-830 
Delmas MA (2009) Research opportunities in the area of governance for sustainable development. In: Delmas MA, Young O (eds) Governance for the environment. New perspectives. Cambridge University Press, Cambridge, pp 221-238

Dreyer M, Selke P, Jönsson AM, Boström M (2011) Structures and processes of stakeholder and public communication on Baltic Sea environmental risks. RISKGOV report, delivery number 10. Södertörn University, Huddinge, Available from: http://www.sh.se/riskgov

Dreyer M, Boström M, Jönsson AM (2014) Participatory deliberation, risk governance and management of the marine region in the EU. J Environ Policy Plan. doi:10.1080/15239 08X.2013.866891

Galaz V, Olsson P, Hahn T, Folke C, Svedin U (2008) The problem of fit among biophysical systems, environmental and resource regimes, and broader governance systems: insights and emerging challenges. In: Young OR, King LA, Schröder H (eds) Institutions and environmental change - principal findings, applications, and research frontiers. MIT Press, Cambridge, pp 147-182

Gilek M, Linke S, Udovyk O, Karlsson M, Lundberg C, Smolarz K, Lemke P (2011) Interactions between risk assessment and risk management for environmental risks in the Baltic Sea. Deliverable 9 within the RISKGOV project. Södertörn University, Huddinge, Available from: http://www.sh.se/riskgov

Gilek M, Karlsson M, Linke S, Smolarz K (2016) Environmental governance of the Baltic Sea: identifying key challenges, research topics and analytical approaches. In: Gilek $\mathrm{M}$ et al (eds) Environmental governance of the Baltic Sea. Springer, Dordrecht

Grin J (2006) Reflexive modernisation as a governance issue, or: designing and shaping restructuration. In: Voss JP, Bauknecht D, Kemp R (eds) Reflexive governance for sustainable development. Edward Elgar, Cheltenham, pp 57-81

Grumbine RE (1994) What is ecosystem management? Conserv Biol 8(1):27-38

Grumbine RE (1997) Reflections on 'what is ecosystem management?'. Conserv Biol 11(1):41-47

Haathi BM, Hedenström E, Linke S, Lundberg C, Reisner G, Wanamo M (2010) Case study report: eutrophication. RISKGOV report. Södertörn University, Huddinge, Available from: http:// www.sh.se/riskgov

Hahn T, Olsson P, Folke C, Johansson K (2006) Trust-building, knowledge generation and organizational innovations: the role of a bridging organization for adaptive comanagement of a wetland landscape around Kristianstad, Sweden. Hum Ecol 34(4):573-592

Hassler B (2003a) Protecting the Baltic Sea - the Helsinki convention and national interests. In: Schram O, Thommessen OB (eds) Yearbook of international co-operation on environment and development 2003-2004. Earthscan, London

Hassler B (2003b) Science and politics of foreign aid - Swedish environmental support to the Baltic states. Kluwer Academic Publishers, Dordrecht

Hassler B (2016) Oil spills from shipping: a case study of the governance of accidental hazards and intentional pollution in the Baltic Sea. In: Gilek M et al (eds) Environmental governance of the Baltic Sea. Springer, Dordrecht

Hassler B, Söderström S, Lepoša N (2010) Marine transportations in the Baltic Sea area. RISKGOV report, delivery number 6. Södertörn University, Huddinge, Available from: http://www.sh.se/ riskgov

Hassler B, Boström M, Grönholm S, Kern K (2011) Environmental risk governance in the Baltic Sea - a comparison among five key areas. RISKGOV report, delivery number 8 . Södertörn University, Huddinge, Available from: http://www.sh.se/riskgov

Hassler B, Boström M, Grönholm S (2013) Towards an ecosystem approach to management in regional marine governance? The Baltic Sea context. J Environ Policy Plan 15(2):225-245

Hjorth R (1992) Building international institutions for environmental protection: the case of Baltic Sea environmental cooperation. Doctoral thesis, Linköping Studies in Arts and Science, Linköping University

Joas M, Jahn D, Kern K (2008) Governance in the Baltic Sea region: balancing between states, cities and peoples. In: Joas M, Jahn D, Kern K (eds) Governing a common sea: environmental policies in the Baltic Sea region. Earthscan, London, pp 3-18 
Jönsson AM, Boström M, Dreyer M, Söderström S (2016) Risk communication and the role of the public: towards inclusive environmental governance of the Baltic Sea? In: Gilek M et al (eds) Environmental governance of the Baltic Sea. Springer, Dordrecht

Karlsson M, Gilek M (2016) Governance of chemicals in the Baltic Sea region: a study of three generations of hazardous substances. In: Gilek M et al (eds) Environmental governance of the Baltic Sea. Springer, Dordrecht

Karlsson M, Gilek M, Lundberg C (2016) Eutrophication and the ecosystem approach to management: a case study of Baltic Sea environmental governance. In: Gilek $M$ et al (eds) Environmental governance of the Baltic Sea. Springer, Dordrecht

Kemp R, Loorbach D (2006) Transition management: a reflexive governance approach. In: Voss JP, Bauknecht D, Kemp R (eds) Reflexive governance for sustainable development. Edward Elgar, Cheltenham, pp 103-130

Kern K (2011) Governance for sustainable development in the Baltic Sea region. J Baltic Stud 42(1):67-81

Kern K, Löffelsend T (2004) Sustainable development in the Baltic Sea region. Governance beyond the nation state. Local Environ 9(5):451-467

Knudsen OF, Hassler B (2011) IMO legislation and its implementation: accident risk, vessel deficiencies and national administrative practices. Mar Policy 35(2):201-207

Lemke P, Smolarz K, Zgrundo A, Wolowicz M (2010) Biodiversity with regard to alien species in the Baltic Sea region. RISKGOV report to BONUS EEIG Programme. University of Gdansk, Institute of Oceanography, Gdynia, Available from: http://www.sh.se/riskgov

Lidskog R, Soneryd L, Uggla Y (2009) Transboundary risk governance. Earthscan, London

Linke S, Gilek M, Karlsson M (2016) Science-policy interfaces in Baltic Sea environmental governance: towards regional cooperation and management of uncertainty? In: Gilek M et al (eds) Environmental governance of the Baltic Sea. Springer, Dordrecht

Mol A (2008) Environmental reform in the information age. The contours of informational governance. Cambridge University Press, New York

Murawski AM (2007) Ten myths concerning ecosystem approaches to marine resources management. Mar Policy 31:681-690

Oberthür S, Gehring T (eds) (2006) Institutional interaction in global environmental governance: synergy and conflict among international and EU policies. MIT Press, Cambridge, MA

Olsson P, Folke C, Berkes F (2004) Adaptive comanagement for building resilience in social-ecological systems. Environ Manag 34(1):75-90

Österblom H, Gårdmark A, Bergström L, Müller-Karulis B, Folke C, Lindegren M, Casini M, Olsson P, Diekmann R, Blenckner T, Humborg C, Möllmann C (2010) Making the ecosystem approach operational - can regime shifts in ecological and governance systems facilitate the transition? Mar Policy 34:1290-1299

Renn O (2008) Risk governance: coping with uncertainty in a complex world. Earthscan, London

Sellke P, Dreyer M, Renn O (2010) Fisheries: a case study of environmental risk governance in the Baltic Sea. RISKGOV report, delivery number 3. Södertörn University, Huddinge, Available from: http://www.sh.se/riskgov

Sellke P, Dreyer M, Linke S (2016) Fisheries: a case study of Baltic Sea environmental governance. In: Gilek M et al (eds) Environmental governance of the Baltic Sea. Springer, Dordrecht

Smolarz K, Biskup P, Zgrundo A (2016) Biological invasions: a case study of Baltic Sea environmental governance. In: Gilek $M$ et al (eds) Environmental governance of the Baltic Sea. Springer, Dordrecht

Stirling A (2009) Participation, precaution and reflexive governance for sustainable development. In: Adger WN, Jordan A (eds) Governing sustainability. Cambridge University Press, New York

Stokke OS (2001) Conclusions. In: Stokke OS (ed) Governing high seas fisheries: the interplay of global and regional regimes. Oxford University Press, Oxford, pp 329-360

Tallis H, Levin PS, Ruckelshaus M, Lester SE, McLeod KL, Fluharty DL, Halpern BS (2010) The many faces of ecosystem-based management: making the process work in real places. Mar Policy 34:340-348 
Udovyk O, Rabilloud L, Gilek M, Karlsson M (2010) Hazardous substances: a case study of environmental risk governance in the Baltic Sea region. RISKGOV report to BONUS EEIG programme. Södertörn University, Sweden

VanDeever SD (2011) Networked Baltic environmental cooperation. J Baltic Stud 42(1):37-55

Voss JP, Kemp R (2006) Sustainability and reflexive governance: introduction. In: Voss JP, Bauknecht D, Kemp R (eds) Reflexive governance for sustainable development. Edward Elgar, Cheltenham, pp 3-28

Voss JP, Bauknecht D, Kemp R (eds) (2006a) Reflexive governance for sustainable development. Edward Elgar, Cheltenham

Voss JP, Kemp R, Bauknecht D (2006b) Reflexive governance: a view on an emerging path. In: Voss JP, Bauknecht D, Kemp R (eds) Reflexive governance for sustainable development. Edward Elgar, Cheltenham, pp 419-437

Walker G, Shove E (2007) Ambivalence, sustainability, and the governance of socio-technical transitions. J Environ Policy Plan 9:213-225

Young O (2002) The institutional dimensions of environmental change: fit, interplay, and scale. MIT Press, Cambridge, MA

Young O (2009) Governance for sustainable development in a world of rising interdependencies. In: Delmas MA, Young O (eds) Governance for the environment. New perspectives. Cambridge University Press, Cambridge 